\title{
광역자치단체 안전감찰제도 정착 및 개선을 위한 정책제언 Policy Suggestions for the Establishment and Improvement of the Safety Audit and Inspection System in Wide-Area Units of the Local Government
}

\author{
이정석* . 김기욱** . 박현정*** \\ Lee, Jeong Seok*, Kim, Keewook**, and Park, Hyun Jung***
}

\begin{abstract}
As various disasters and safety accidents frequently occur, people's expectations regarding safety management are gradually increasing. The importance of disaster and safety management is especially magnified due to successive accidents. These include fires in complex buildings and hospitals, inversion of cranes, paralysis of a communication network by a fire in the KT underground cable tunnel, rupture of pipelines in district heating systems, derailment of a KTX train, etc. To strengthen the generalization and mediation functions for disaster management and improve the disaster management system, the Ministry of the Interior and Safety introduced the safety audit and inspection system. This study suggests plans for the establishment and improvement of the system in the early part of its implementation. This includes a theoretical discussion on the safety audit and inspection, an investigation of the current organization in Wide-Area Units of the Local Government, and drawing plans for the establishment and improvement of the system. As a result, efficient planning for the safety audit and inspection, expansion of manpower, enhancement of the organization's status, and establishment of a system for the safety audit and inspection were suggested.
\end{abstract}

Key words : Disasters and Safety Accidents, Safety Audit and Inspection System, Wide-Area Units of the Local Government

\section{요 지}

최근 각종 재난 및 안전사고가 빈번하게 발생함에 따라 안전에 대한 국민의 기대수준이 높아지고 있는 상황이다. 특히 복합건물 및 병원 화재, 크레인 전도, KT 지하 통신구 화재에 의한 통신망 마비, 지역난방 열 수송관 파열, KTX 강릉선 열차 탈선 등 연이은 사고가 발생함에 따라 재난·안전관리의 중요성이 부각되고 있다. 이에 행정안전부는 재난안전 총괄·조정 기능 강화 및 고질적으로 반복되는 재난관리체계의 문제점을 개선하기 위해 안전감찰제도를 도입하였다. 본 연구에서는 광역자치단체 안전감찰제도의 시행 초기에 제도의 원활한 정착과 개선을 위한 방안을 제시하였다. 이를 위해 안전감찰의 이론적 논의 및 광역자치단체 안전감찰 전담조직 현황조사를 통해 시사점을 제시하고, 제도 정착 및 개선을 위한 방안을 도출하였다. 연구의 결과로 효율적 감찰계획 수립, 전담조직 인력 확충, 전담조직 위상 제고, 안전감찰 체계 확립의 중요성을 제시하였으며, 각 사항을 위한 방안을 논의하였다.

핵심용어 : 재난 및 안전사고, 안전감찰제도, 광역자치단체

*정회원, 부산연구원 연구위원(E-mail: jslee@bdi.re.kr)

Member, Research Fellow, Busan Development Institute

**교신저자, 정회원, 부산연구원 연구위원(Tel: +82-51-860-8700, Fax: +82-51-860-8787, E-mail: kkim@bdi.re.kr)

Corresponding Author, Member, Research Fellow, Busan Development Institute

***부산연구원 연구원

Researcher, Busan Development Institute 


\section{1. 서 론}

최근 각종 재난 및 안전사고가 빈번하게 발생함에 따라 안전에 대한 국민의 기대수준이 높아지고 있는 상황이다. 기후변화가 진행됨에 따라 자연재난의 규모 및 강도가 증가 하고 있으며, 문명의 발달에 따른 첨단기기 및 기술 등의 이용에 의한 편익이 증가하는 반면, 이에 동반하는 다양한 위험이 동시에 존재하고 있다(Kim and Lee, 2019). 최근 복합건물 및 병원 화재, 크레인 전도 $\mathrm{KT}$ 지하 통신구 화재에 의한 통신망 마비, 지역난방 열 수송관 파열, KTX 강릉선 열차 탈선 등 연이은 사고가 발생함에 따라 재난 - 안전관리 의 중요성이 부각되고 있다. 이에 행정안전부는 재난안전 총괄 - 조정 기능 강화 및 고질적으로 반복되는 재난관리체 계의 문제점을 개선하기 위해 안전감찰제도를 도입하였다 (MOIS, 2017).

안전감찰제도는 재난관리책임기관 및 그 소속 공무원 · 직원의 위법 - 부당한 행위를 적발하여 기관경고 하거나, 징계 등을 요구하여 정부 및 지방자치단체의 재난안전시스 템이 제대로 작동하도록 하는 제도(MOIS, 2017)로서 행정안 전부 및 광역자치단체의 안전감찰활동에 의해 수행된다. 안전감찰활동의 근거는 「헌법 제 34 조 제6항, 「재난 및 안전 관리 기본법 (이하, 기본법) 제 4 조 및 제 77 조 제 1 항 - 제 2 항, 「재난관리 의무 위반 처분에 관한 규칙」(이하, 처분규칙)에 서 찾아볼 수 있다. 현재 광역자치단체의 안전감찰활동은 2018년 4월 26일 행정안전부로부터 송달된 「안전감찰 전담 조직 설치 및 운영지침」(이하, 행정안전부 지침)에 따라 구성된 전담조직에 의해 수행되고 있다. 하지만 안전감찰 전담조직의 구성 및 운영이 초기단계이며, 감찰의 대상 기관 및 업무가 매우 광범위하여 감찰의 수행에 많은 어려움을 겪고 있다. 따라서 광역자치단체 안전감찰제도의 정착 및 개선을 위한 연구가 시급한 상황이다.

안전감찰제도에 대한 기존의 연구는 매우 제한적인 상황 이다. Lee et al. (2015)은 행정안전부(구, 국민안전처)에서 안전감찰제도를 시행하기 위해 수행된 연구에서 안전감찰 의 개념 및 기능-효과, 제도의 정당성, 운영방안 등에 대한 연구를 수행하였다. 하지만 중앙정부에서의 안전감찰 수행 을 위한 연구결과를 조직, 인력 등 행정능력이 상이한 광역자 치단체에 그대로 적용하는 데에는 한계가 있다. 최근 광역자 치단체의 안전감찰에 대한 연구가 수행되고 있으나, 이 또한 많은 사례를 찾아보기는 어려운 상황이다. Cho (2018)는 안전 환경 진단과 대형사고 원인분석을 통해 충청남도가 안전감찰활동을 위해 지향해야 할 기본방향을 제시하고, 목표에 따른 전략과 세부 실행과제(감찰과제)를 선정하였 다. 하지만 이 연구는 감찰과제 선정을 위한 일종의 실행계획 으로 안전감찰제도의 정착과 개선에 필요한 방안의 도출에 는 한계를 가진다. Kim (2018)은 안전감찰제도의 도입배경 을 설명하고 부산시에서 안전 분야 부패 근절을 위한 과제로
정기적 - 수시적 감찰과제 선정, 안전감찰 전담조직 운영방 안 마련, 안전감찰 홍보·교육방안 마련의 필요성을 제시하 였다. Kim and Choi (2019)는 안전감찰제도의 필요성을 제시하고 제도의 선진화를 위한 방안으로 안전감찰의 예방 적 기능 강화, 계획에 따른 감찰활동 및 활동에 대한 점검, 결과 및 처분기준에 대한 합리화- 표준화, 감찰활동을 위한 협력체계 구축 등을 제안하였으며, 기존의 안전점검, 안전관 리에서의 안전감찰의 역할 설정의 중요성을 제시하였다. 하지만 Kim (2018)과 Kim and Choi (2019)는 여러 가지 방안 마련의 필요성만을 제시하였을 뿐, 각 사항에 대한 구체적 내용을 도출하지는 못하였다는 한계를 가진다.

본 연구에서는 기존 연구들의 한계를 보완하고 구체화하 기 위해 광역자치단체 안전감찰제도 시행 초기에 제도의 효과적인 정착 및 개선을 위한 방안을 제시하고자 하였다. 이를 위해 (1) 안전감찰의 정의 및 내용을 포함하는 이론적 논의를 통해 안전감찰의 개념을 살펴보았으며, (2) 광역자치 단체 안전감찰 전담조직 현황조사를 통해 개선이 필요한 문제점을 제시하고, (3) 제시된 문제점들의 개선을 위한 방안을 도출하여 효과적인 제도 정착을 위한 기반을 마련하 고자 하였다.

\section{2. 안전감찰의 이론적 논의}

\section{1 안전감찰의 정의}

기존의 문헌 및 법령에서 안전감찰을 다양하게 정의하고 있으나 그 내용은 유사하게 나타난다. Lee et al. (2015)은 '국민안전처의 안전감찰담당관이 재난 - 안전에 관한 총괄· 조정적 업무의 일환으로 관계 중앙행정기관이나 지방자치단 체 또는 공공기관이 수행하는 재난·안전관리 업무를 제 3 자 적 입장에서 적부를 조사한 후 그 결과를 처리하는 활동'으로 정의하였으며, MOIS (2017)는 재난관리책임기관 및 그 소속 공무원 - 직원의 위법 - 부당한 행위를 적발하여 기관경고 하 거나, 징계 등을 요구하여 정부 및 지방자치단체의 재난안전 시스템이 제대로 작동하도록 하는 일종의 감독기능'으로 정의 하였다. 법령에서의 정의를 살펴보면, 처분규칙 제 2 조는 안전 감찰을 '기본법 제 3 조 제 5 호에 따른 재난관리책임기관에서 필요한 조치를 하지 아니하는 등 업무 처리에 문제가 있었던 경우 조사·평가 등의 방법으로 확인하여 재난 및 안전 관리에 관한 문제점을 시정·개선하도록 하는 일체의 행위'로 정의 하고 있다.

기존 문헌 및 법령에서 나타나는 다양한 정의와 안전감찰 의 기능 및 효과(Lee et al., 2015)를 종합해 보면, 안전감찰을 '기본법에서 규정하는 재난관리책임기관의 업무에 대한 정 기적 - 수시적 점검을 통해 반복적 안전 관련 위법사항 및 사고발생 원인의 자율적 시정을 위한 체계 마련, 안전관리 순환체계(계획, 집행, 사후관리 등)에서 발견된 문제점에 대한 환류(feedback), 감찰 사례 확산 및 교육을 통한 업무능 
력 항상 등의 목적을 가지는 재난 및 안전사고의 사전방지를 위한 계도적 차원의 예방적 감찰'로 정의할 수 있다.

\section{2 안전감찰의 내용}

\subsection{1 안전감찰의 범위}

정부 및 지방자치단체에서 수행되는 통상의 감사 및 감찰활 동이 행정기관 또는 소속 직원의 직무 전반을 조사· 평가하는 것과 달리 안전감찰은 그 분야가 재난안전분야로 한정된다 (MOIS, 2017). 기본법 제 77 조 제 2 항은 안전감찰의 대상을 '재난관리책임기관'으로, 업무범위를 '이 법에 따른 재난예방 조치 - 재난응급조치 - 안전점검 - 재난상황관리 - 재난복 구 등의 업무로 규정하고 있다. 이와 같이 안전감찰의 대상 및 업무 범위가 법령에 의해 제한되어 있으나, 실제로 매우 광범위한 실정이다(Kim and Lee, 2019 <표 부록-2> 참고).

\subsection{2 안전감찰의 절차}

Lee et al. (2015)와 MOIS (2017)은 '감찰 계획 수립 - 보 고', '감찰 활동', ‘처분 양정 심사위원회 개최' '관계기관 협의', '감찰 결과 보고', ‘처분요구서 작성 통보 및 사후관리' 로 구성되는 안전감찰의 진행절차를 제시하였다. 이는 중앙 정부의 조직에 따라 제시된 것으로, 부산시의 경우 기존 감사의 절차를 그대로 준용하고 있는 상황이다. 따라서 광역 자치단체의 조직을 반영한 표준화된 감찰의 진행절차를 마련할 필요가 있다.

\section{3. 광역자치단체 안전감찰 전담조직 현황}

2018년 4월 26일 행정안전부 지침이 송달됨에 따라 전국 16 개 광역자치단체(서울 제외, 기 운영)에 전담조직이 신설 되어 현재 모든 광역자치단체에서 조직이 운영 중에 있다 (Table 1). 전담조직 현황을 살펴보면 2015년부터 전담조직 을 기 운영 중인 서울시를 제외하고 모두 최근에 조직 구성이 완료되었는데, 적게는 2 명에서 많게는 6 명으로 구성되어 있는 것을 알 수 있다. 특히 인천, 대전, 울산 등 여덟 개 광역자치단체에서는 4 명 이상으로 조직하도록 정한 행정안 전부 지침과 다르게 3 명 이하의 규모로 운영되고 있어 추후 인력 보강이 필요하며, 서울시를 제외한 타 광역자치단체의 경우에도 2장에서 설명한 안전감찰의 범위를 감안할 때, 인력의 보강이 필요할 것으로 보인다.

\section{4. 현행 안전감찰제도 및 전담조직 운영상의 문제점}

본 장에서는 2 장 및 3 장에서 소개한 안전감찰의 정의, 범위, 절차, 안전감찰 전담조직 현황을 고려하여 현행 안전감 찰제도 및 전담조직 운영상의 문제점을 제시하였다.

\section{1 안전감찰의 대상 및 범위}

\subsection{1 광범위한 업무의 대상 및 범위}

2.2.1절에서 설명한 바와 같이 안전감찰의 대상 및 업무 범위가 법령에 의해 제한되어 있으나, 실제로 매우 광범위한 실정이다. 일례로, 부산시의 경우 관할 재난관리책임기관이 총 60 개이며, 기본법에서 규정하는 재난관리책임기관의 업 무가 총 85개(Kim and Lee, 2019)로 업무의 대상 및 범위가 광범위하며1), 타 광역자치단체의 경우도 마찬가지인 것으 로 파악되었다.

Lee et al. (2015)은 안전감찰의 대상 및 업무가 광범위함에 따라 이중감찰, 비용증대, 안전관리 불신 등으로 인한 사기 저하가 발생할 우려가 있음을 지적하였다. 따라서 감찰의 효율성 확보를 통한 문제의 완화가 필요하다.

\subsection{2 대상 및 업무의 중복}

서울시를 제외한 광역자치단체 안전감찰 전담조직의 현 재 업무범위2)는 안전감찰 계획수립 및 추진, 재난관리책임 기관의 안전 관련 의무위반행위에 대한 조사 및 징계요구, 안전 분야 부패방지, 안전감찰 제도개선 및 사후관리, 중앙부 처 안전감찰 관련업무 지원 등으로 유사하게 나타나고 있다. 이는 기존에 수행되어 왔던 기술감사, 안전관리, 일상감사 등의 업무에서 안전과 관련된 업무를 이관하여 집중적으로 수행하고자 하는 의도이나, 안전감찰과 유사한 성격을 가지 며 그 경계가 모호하고 중복되는 이들 업무가 타 조직에서 여전히 수행되고 있어 업무효율의 저하가 발생할 수 있을 것으로 보인다. 3$)$

반면, 서울시의 경우 2015년부터 안전감찰 전담조직의 운영을 시작하여 그간 제도의 정착이 다소 이루어진 것으로 판단된다. 전담조직의 업무가 안전 관련 일상감사 및 하도급 에 대한 감사업무를 포함하며, 안전감찰, 기술감사, 안전관 리 등 안전감찰 유관업무의 통합을 통해 업무의 효율성을 확보하고 있는 것으로 조사되었다. 특히 타 광역자치단체에 비하여 많은 인력을 전담조직에 배치하여 업무의 분업 및 업무분야의 확장이 수월한 것으로 판단된다.

\section{2 안전감찰 인력배치}

\subsection{1 인력 부족}

Table 1로부터 알 수 있는 바와 같이 서울시를 제외한 모든 광역자치단체에서 2 6명으로 구성된 전담조직을 운

1) 부산시 전담조직 공무원과의 면담 결과, 업무가 광범위하여 실제로 제한적인 업무만을 수행하고 있는 것으로 조사됨.

2) 각 광역자치단체 조직도 웹페이지 및 행정기구 설치 관련 조례의 분장 사무 참고

3) 부산시 전담조직 공무원과의 면담 결과, 특정 업무의 경우 타 조직에 서 이미 수행되고 있어 안전감찰의 범위에 포함됨에도 불구하고 수행 이 어려운 것으로 나타남. 
Table 1. Safety Audit and Inspection Teams in Municipal Governments

\begin{tabular}{|c|c|c|c|}
\hline \begin{tabular}{c|} 
Local \\
government
\end{tabular} & $\begin{array}{l}\# \text { of } \\
\text { staff }\end{array}$ & $\begin{array}{l}\text { \# of staff by specialty } \\
\text { (alphabetical order) }\end{array}$ & Department and team \\
\hline Seoul & 37 & $\begin{array}{l}\text { Admin } 17, \text { Arch } 5 \text {, Atty } \\
\text { 2, CE } 12, \text { EE } 1\end{array}$ & Safety Audit \& Inspection Division, Audit \& Inspection Commission \\
\hline Busan & 5 & Arch 3, CE 2 & Inspection 3-Team, Inspection Division, Audit \& Inspection Bureau \\
\hline Daegu & 4 & Admin 1, CE 3 & Safety Inspection Team, Safety Policy Officer, Citizen Safety Office \\
\hline Incheon & 3 & Admin 1, Arch 1, DP 1 & Safety Inspection Charge, Safety Policy Division, Citizen Safety Headquarters \\
\hline Gwangju & 4 & Admin 2, Arch 1, CE 1 & $\begin{array}{l}\text { Safety Inspection Charge, Disaster Prevention Division, Citizens' Safety } \\
\text { Bureau }\end{array}$ \\
\hline Daejeon & 3 & Arch $1, \mathrm{CE} 2$ & Safety Inspection Team, Safety Policy Division, Office for Public Safety \\
\hline Ulsan & 3 & Arch 1, CE 1, ME 1 & Safety Inspection Charge, General Safety Division, Public Safety Office \\
\hline Sejong & 4 & Admin 2, CE 2 & Safety Inspection Charge, Safety Policy Division, Civil Safety Bureau \\
\hline Gyeonggi & 6 & $\begin{array}{c}\text { ChE 1, CE 2, DP 1, FF } \\
1, \mathrm{ME} 1\end{array}$ & $\begin{array}{l}\text { Safety Inspection Team, Mobile Safety Inspection Division, Safety } \\
\text { Management Office }\end{array}$ \\
\hline Gangwon & 3 & Admin 1, Arch 1, FF 1 & $\begin{array}{l}\text { Safety Inspection Team, Safety Management Division, Disaster and Safety } \\
\text { Management Office }\end{array}$ \\
\hline Chungbuk & 3 & Admin 3 & $\begin{array}{l}\text { Safety Inspection Team, Safety Policy Division, Disaster and Safety } \\
\text { Management Office }\end{array}$ \\
\hline Chungnam & 3 & Admin 1, Arch 1, CE 1 & $\begin{array}{l}\text { Safety Inspection Team, Safety Policy Division, Disaster and Safety } \\
\text { Management Office }\end{array}$ \\
\hline Jeonbuk & 2 & Arch 1, CE 1 & Safety Inspection Team, Safety Policy Officer, Resident Safety Bureau \\
\hline Jeonnam & 5 & Admin 3, Arch 2 & Safety Inspection Team, Safety Policy Division, Director of Public Safety \\
\hline Gyeongbuk & 3 & Admin 1, CE 2 & Safety Inspection Team, Division of Safety Policy, Resident Safety Bureau \\
\hline Gyeongnam & 4 & Admin 1, Arch 1, CE 2 & $\begin{array}{l}\text { Safety Inspection Charge, Public Welfare and Safety Inspection Division, } \\
\text { Emergency and Security Construction Bureau }\end{array}$ \\
\hline Jeju & 4 & Admin 2, FF 1 , Police 1 & $\begin{array}{l}\text { Safety Inspection Team, Integrity Reform Officer, Communication Reform } \\
\text { Policy Officer }\end{array}$ \\
\hline
\end{tabular}

* Source: Organization charts in each municipal government webpage and phone survey (2019.3.4.)

* Admin: Administration; Arch: Architecture; Atty: Attorney; CE: Civil Engineering; ChE: Chemical Engineering; DP: Disaster Prevention; EE: Electrical Engineering; FF: Firefighting; ME: Mechanical Engineering

영하고 있어 방대한 안전감찰 업무를 효과적으로 수행하는 것은 현실적으로 무리이다. 서울시의 경우 안전감찰을 담당하 는 안전감사담당관이 6 팀 37명으로 구성되어 운영되고 있어, 안전감찰의 광범위성과 효율적인 업무 수행을 감안할 때 서울시의 인력수준이 더 적절하다고 할 수 있다. 물론 인구, 면적, 공무원 수 등 광역자치단체 특성에 따라 전담조직의 규모가 달라져야 하지만, 안전감찰의 업무범위와 현재 전담조 직의 인력 현황을 고려하면, 궁극적으로 전담조직의 인력 확충이 필요하다는 점은 분명한 것으로 판단된다.4)

\subsection{2 특정 직렬에의 인력 집중}

공무원 직렬에 따른 전담조직 인력배치(Table 1)를 보면, 행정 및 시설(토목 및 건축)직렬이 주로 배치되어 있으며,

4) 부산시 전담조직 공무원과의 면담 결과, 업무의 범위에 비하여 매우 부족한 인력 확충이 시급한 것으로 조사됨.
드물게 공업(전기, 화공 등), 방재, 소방, 경찰 등의 직렬이 배치되어 있는 것을 알 수 있다. 총 96 명의 전담조직 공무원이 행정직렬 36명, 시설직렬 48명, 공업직렬 4명, 방재직렬 2명, 소방직 3 명, 경찰직 1 명, 변호사 2 명으로 구성되어 있다. 서울시의 경우 임기제 전문직 공무원으로 변호사 2 명을 배치 하여 법적 문제를 검토하고 있는 것으로 나타났다.

총 17 개 광역자치단체 중 11 개에서 행정 및 시설직렬 공무원만을 배치하고 있으며, 이 중 3 개에서는 행정 혹은 시설직렬만을 배치하고 있어 전담조직의 직렬편중이 심각한 것으로 나타났다. 다양한 시설, 요소, 재난, 안전관리체계 등에 대한 점검을 실시하는 안전감찰의 특성상 소수 직렬에 편중된 인력배치는 부적절한 것으로 판단된다.5) 따라서 광역 자치단체별로 필요직렬을 고려한 인력충원이 필요하며, 인

5) 부산시 전담조직 공무원과의 면담 결과, 전기, 기계, 소방 등 직렬의 배치가 시급한 것으로 조사됨. 
력충원 시 직렬별 최소 1 명 배치, 변호사 배치 등의 방안을 고려해야 한다.

\section{3 안전감찰 전담조직의 위상}

재난관리책임기관의 안전관리업무에 대한 감찰을 수행 하는 광역자치단체 안전감찰 전담조직은 경우에 따라 광역 자치단체 관련부서에 대한 감찰을 수행할 필요가 있으므로 조직의 위상이 중요한 것으로 판단된다. 현재 전담조직의 위상은 광역자치단체에 따라 상이하게 나타난다. 서울시의 경우 안전감사담당관이 시장 직속 감사위원회에 소속되어 있으며, 제주도의 경우 안전감찰팀이 소속된 청렴혁신담당 관이 도지사 직속 소통혁신정책관에 소속되어 있다. 또한 부산시의 경우 전담조직인 조사 3 팀이 행정부시장 직속 감사 위원회로 이관(2019.1.9. 일자)되어 운영 중이다. 이와 같이 서울시, 부산시, 제주도의 경우, 전담조직이 (부)시장 - 도지 사 직속기구에 설치되어 감찰의 독립성 및 공정성 확보가 수월할 것으로 판단된다.

이를 제외한 타 광역자치단체의 경우, 전담조직이 재난· 안전 담당 본부·실 - 국 내 팀 혹은 담당으로 설치되어 있는 것으로 나타났다. 이러한 경우 감찰과제에 따라 동일부 서 또는 상위조직을 감찰하게 되어 감찰의 독립성 및 공정성 확보가 어려운 상황이 발생할 수 있을 것으로 보인다.6) 반면 해당 본부 - 실 - 국 내 재난 · 안전 담당 과와의 협업이 용이하여 연계성, 기동성 등 업무의 효율성 확보에 대한 장점이 존재할 것으로 판단된다.

이와 같이 전담조직의 위상에 따라 감찰업무 수행에 장단 점이 존재하는 것으로 판단된다. 따라서 업무의 독립성, 공정성, 효율성 확보를 고려한 감찰조직의 위상 제고가 필요 하다.

\section{5. 제도 정착 및 개선을 위한 전담조직 운영방안}

본 장에서는 4장에서 제시된 현행 안전감찰제도 및 전담조 직 운영상의 문제점 및 이를 해결하기 위한 방안을 Fig. 1 과 같이 제시하고 각 방안에 대한 구체적인 실행방안을 제시하 고자 하였다.

\section{1 효율적 감찰계획 수립}

앞에서 논의한 바와 같이 법령에서 규정하고 있는 안전감 찰의 범위는 매우 넓은데 반하여 현재의 광역자치단체 전담 조직 규모는 매우 작은 상황이다. 장기적으로 전담조직의 인력 확충을 통한 업무수행범위의 확대가 필요하지만 단기 적 해법으로 효율적 감찰계획의 수립이 필요하다.

현재 광역자치단체에서 수행되고 있는 안전감찰과제는 풍수해, 지진 등 자연재난 대비실태, 도로교통사고, 화재

6) 부산시 전담조직의 이관 이전에 동일부서 혹은 상위조직 감찰에 대한 어려움이 있었던 것으로 조사됨.
등 사회재난 대비실태 등 다양한 재난을 대상으로 하고 있으며, 감찰의 대상이 되는 시설 및 요소도 방재시스템, 시설물, 건설공사장, 사업성과, 사후관리 등으로 매우 다양 하게 나타난다(Kim and Lee, 2019). 하지만 전담조직 인력의 한계에 의해 제한된 분야 및 업무에 대한 감찰과 현안에 따른 과제(특정감사 등)가 혼재되어 수행되고 있다.

이와 같은 문제를 완화하기 위해 안전감찰과제를 (1) 수행 시기를 지정할 필요가 있거나 주기적인 점검이 필요한 분야 를 대상으로 하는 정기과제(풍수해 대비 안전관리실태 점검, 혹한기 대비 안전관리실태 점검 등), (2) 수행 시기의 제약이 없고 연중 일관된 안전관리가 요구되는 분야를 대상으로 하는 수시과제(방재시스템 작동상태 점검, 다중이용시설 안전관리실태 점검 등)로 구분할 필요가 있다. 이를 통해 계획에 따른 정기과제를 수행하고 업무량에 따라 수시과제 를 선택적으로 수행하여 전담조직의 업무 부담을 조정 - 완 화할 수 있다. 시행 초기에는 정기과제의 수를 축소하여 업무 부담을 줄이고 제도 정착 및 인력 확충에 따라 이를 점차 확대하는 방안도 고려할 수 있다.

\section{2 전담조직 인력 확충}

4.2.1절에서 언급한 바와 같이 전담조직의 인력 확충이 필요한 상황이지만 이는 총액인건비 내에서 인력, 조직, 기구를 운영해야 하는 지방자치단체의 상황으로 인해 쉽지 않은 것이 사실이다. 따라서 인력 확충을 위한 단계적 계획 수립을 통한 방안을 모색할 필요가 있다.

먼저 광역자치단체별로 소수의 인원(2 3명)을 추가로 확보하기 위한 노력이 필요하다. 이 때 현 조직에 부족한 직렬(특히 소방, 전기, 기계 등)을 중심으로 하는 인력 확충이 필요하며, 이를 위해 기획 및 인사 부서와의 지속적인 협의가 필요하다. 인력 확충을 위한 대상은 광역자치단체 내 각 과에서 안전 관련 업무를 수행하고 있는 공무원이 적절할 것으로 판단된다.

다음으로 안전감찰제도가 정착되어감에 따라 업무의 확 장이 필요하며, 이를 위한 인력 확충, 조직 확장, 예산 지원 등이 필요하다. 앞에서 논의한 바와 같이 현재 안전감찰과 유사한 성격을 가지며 그 경계가 모호하고 중복되는 기술감 사, 안전관리, 일상감사 등의 업무가 타 조직에서 수행되고 있어 업무의 효율성에 영향을 줄 수 있다. 따라서 유사 업무를 수행하는 조직의 통합('과' 단위의 조직 신설)을 통한 인력 확충 및 조직 확장을 고려할 필요가 있으며, 이를 통해 업무의 확장 또한 기대할 수 있다.

\section{3 전담조직 위상 제고}

\subsection{1 조직 통합 및 이관을 통한 위상 제고}

현재 서울시를 제외한 모든 광역자치단체의 안전감찰 전담조직은 팀 - 담당 단위로 운영되고 있으며, 서울시, 부산 


\begin{tabular}{|c|c|c|}
\hline Subjects and Scope of the Business & & $\begin{array}{l}\text { Efficient Planning for the Safety Audit and Inspection } \\
\text { - Reduce work load of the organization by separating regular } \\
\text { and occasional subjects }\end{array}$ \\
\hline $\begin{array}{l}\text { - Broad subjects and scope } \\
\text { - Overlap of subjects and scope }\end{array}$ & $\gg$ & $\begin{array}{l}\text { Establishment of a System for the Safety Audit and Inspection } \\
\text { - Clarify the subjects and scope of the business } \\
\text { - Classify the system into three stages/phases }\end{array}$ \\
\hline $\begin{array}{l}\text { Arrangement of Manpower } \\
\text { - Lack of manpower } \\
\text { - limited to some specialties }\end{array}$ & $\gg$ & $\begin{array}{l}\text { Expansion of Manpower } \\
\text { - Expand manpower by stages } \\
\text { - Supply workers with required specialties } \\
\text { - Integrate organizations with similar or overlapped businesses }\end{array}$ \\
\hline $\begin{array}{l}\text { Status of the Organization } \\
\text { - Pros and cons by the status }\end{array}$ & $\gg$ & $\begin{array}{l}\text { Enhancement of the Organization's Status } \\
\text { - Integration and transference of organizations } \\
\text { - Designation of special judicial police officers } \\
\text { - Revision of the related acts }\end{array}$ \\
\hline
\end{tabular}

Fig. 1. Issues of the Current Safety Audit and Inspection System and its Suggested Solutions

시, 제주도를 제외한 광역자치단체의 전담조직이 재난·안 전 담당 본부·실·국에 설치되어 있어 업무의 독립성과 공정성에 영향을 줄 수 있다. 감찰의 특성상 업무의 독립성과 공정성을 확보하는 것이 무엇보다 중요하다는 점을 감안할 때, 조직 위상의 제고가 매우 중요하며, 이를 위해 조직 통합을 통한 위상 강화 및 업무의 효율성 확보(5.2절 참고), (부)시장 - 도지사 직속 조직 구성(이관)을 통한 업무의 독립 성, 공정성 확보가 필요하다.

\subsection{2 특별사법경찰관리의 지명}

전담조직의 위상제고를 위한 하나의 방안으로 전담조직 공무원의 특별사법경찰관리 지명을 들 수 있다.7) 최근 재난 - 안전 분야에서의 예방이 강조되고 있는 상황에서 안전감 찰의 계도적 - 예방적 기능을 강화하기 위해 전담조직 공무 원에게 조사·단속 권한을 부여할 필요가 있다. 이를 통해 안전점검 및 예방의 중요성을 강조하고 재난관리책임기관 의 점검 거부·기피·방해 등의 행위를 억제하여 전담조직 의 역할을 원활한 수행을 기대할 수 있다.

전담조직 공무원의 특별사법경찰관리 지명이 필요한 반 면, 이에 따른 권력 오·남용의 소지 및 지역주민들의 인식 부족 또한 존재하므로 이에 대한 대응책이 필요하다. Lee et al. (2015)은 수사에 관한 전문성이나 경험이 부족한 특별 사법경찰관리는 필요최소한의 범위에서 보충적으로 운영되

7) Yang and Kim (2019)의 연구는 특사경의 직무 범위가 지속적으로 확장 되어왔고, 특사경 활동이 행정의 집행력 강화뿐만 아니라 안전한 도 시 구현에 매우 큰 역할을 했다고 평가하였음. 즉, 특사경의 양적 팽창 및 긍정적 기여 측면을 고려할 때, 그 가능성은 충분히 열려 있다고 판단됨.
어야 하며, 특별사법경찰관리에 대한 감독의 강화가 필요하 다고 하였다. Park et al. (2012)은 특별사법경찰관리가 국민 에 대해 자유박탈이 가능한 강제처분권한을 부여받고 있으 므로 강제처분을 함에 있어서 적법절차를 준수하도록 전담 공무원의 의식 전환이 필요하다고 하였다. 또한 특별사법경 찰제도에 대한 대국민 홍보를 통한 국민의 이해와 협조를 바탕으로, 전담공무원들이 열정과 사명을 가지고 일할 수 있는 환경조성이 필요하다고 강조하였다. 따라서 특별사법 경찰관리의 적법절차 준수 및 인권침해 방지를 위한 노력과 함께 감찰 전후 사전결제 및 사후보고체계 등 광역자치단체 차원에서의 이중적 규제 장치를 마련할 필요가 있다.

\subsection{3 관계법령 보완}

광역자치단체의 안전감찰활동은 기본법, 기본법 시행령, 기본법 시행규칙 및 처분규칙에 근거하여 이루어지고 있다. 기본법 제 77 조 제 2 항은 광역자치단체장의 징계요구권을 규정하고 있고, 기본법 시행령은 징계 요구의 통보 등에 대한 자세한 사항을 시행규칙에 위임하고 있으며, 기본법 시행규칙에서 징계 요구 통보에 필요한 사항을 별도의 행정 안전부령으로 고시하도록 하고 있다. 하지만 해당 '징계 요구' 부분을 다루고 있는 처분규칙 제 3 조에서는 광역자치 단체장의 역할을 누락하고 있어 이에 대한 법령의 보완이 필요한 상황이다.

한편, 광역자치단체장의 역할에 대한 상위법령의 위임조 항이 없다는 점이 2018년 10월 4일 행정안전부의 주관으로 개최된 안전감찰 워크숍 및 공문으로 문제제기 된 후, 행정안 전부에서 시행규칙 개정을 추진 중인 것으로 나타났다 $(\mathrm{Lim}$, 
2018). 따라서 향후 규칙 제 - 개정 시 지역 특성이 반영될 수 있도록 표준규칙안에 대한 광역자치단체 차원의 의견 검토와 함께 재난관리책임기관을 대상으로 한 지역 차원의 의견 수렴이 동시에 진행될 필요가 있다.

\section{4 안전감찰 체계 확립}

전술한 바와 같이 안전감찰제도 시행 초기에 제도의 원활한 정착 및 개선을 위해서는 감찰 대상 기관 및 업무의 범위를 명확하게 할 필요가 있으며, 이는 전담조직의 업무 부담을 고려하여 이루어져야 한다. 하지만 현재 수행되고 있는 안전감찰의 내용을 보면 재난관리책임기관뿐만 아니 라 실제 현장 - 시설에서의 안전관리업무에 대한 감찰 - 점 검을 포함하여 업무의 범위가 매우 방대하며, 기존의 기술 감사, 안전점검 등의 업무와 중복되는 부분이 존재한다. 안전감찰 수행 시 경우에 따라 현장- 시설에 대한 직접감찰 이 필요할 수 있으나 전담조직 인력, 업무 중복성 등을 고려하면 업무 분산을 통한 감찰업무의 최소화 - 효율화가 필요해 보인다. 감찰업무의 최소화 - 효율화가 제대로 이루 어지지 않으면 전담조직뿐만 아니라 각 재난관리책임기관 의 재난 - 안전관련 부서의 업무 또한 가중될 수 있으므로, 한정된 인원으로 운영되는 감찰업무 및 재난관리책임기관 의 재난·안전관련 부서 업무의 효율성 확보를 위해 현장 - 시설에서의 자체점검, 재난관리책임기관의 현장 - 시설 점검, 전담조직의 안전감찰로 이어지는 안전감찰의 체계 (Fig. 2)를 확립할 필요가 있다.

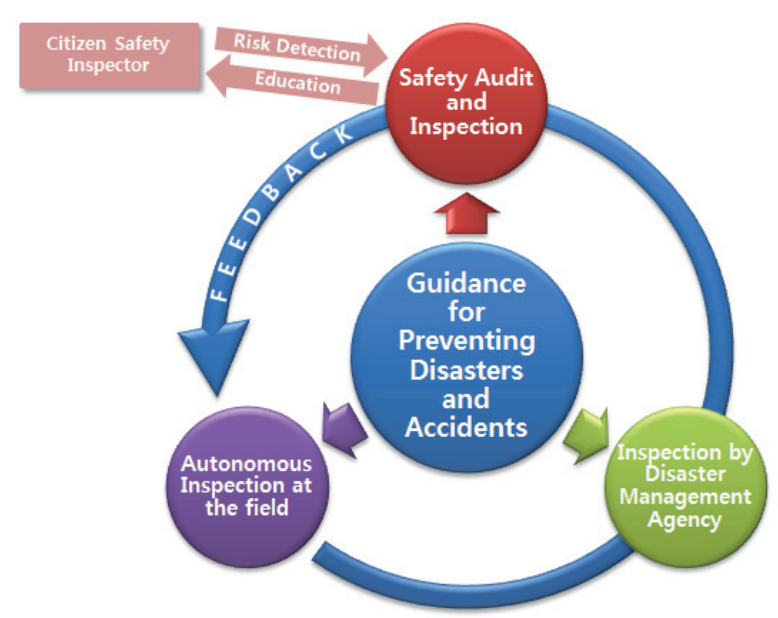

Fig. 2. Structure of the Safety Audit and Inspection

안전감찰의 체계를 Fig. 2와 같이 세 단계로 나눔으로써 전담조직의 업무부담 완화를 통한 감찰업무의 충실한 수행; 기술감사, 안전점검 등 기존 안전 관련 감사- 점검업무와의 업무중복 완화 및 이중감사 지양, 현장 - 시설 및 재난관리책 임기관의 자체점검 기능 강화에 따른 자율적 안전관리 풍토 조성 및 이에 따른 사고방지의 연속성 확보. 감찰 결과 환류
및 사후관리, 수범사례 홍보를 통한 현장- 시설, 재난관리책 임기관의 자체적 안전관리 기능 보완 - 향상 계도(feedback); 재난 - 사고 예방 및 재발 방지; (가칭) ‘시민안전감찰관'의 위험감지 및 제보에 따른 안전 사각지대 축소 등과 같은 효과를 기대할 수 있다.

\section{6. 결 론}

본 연구에서는 광역자치단체 안전감찰제도의 시행 초기 에 제도의 원활한 정착과 개선을 위한 방안을 제시하였다. 이를 위해 안전감찰의 이론적 논의 및 광역자치단체 안전감 찰 전담조직 현황조사를 통해 시사점을 제시하고, 이를 통해 제도 정착 및 개선을 위한 방안을 도출하였다.

연구의 결과로 효율적 감찰계획 수립, 전담조직 인력 확충, 전담조직 위상 제고, 안전감찰 체계 확립의 중요성을 제시하 였으며, 각 사항을 위한 방안을 논의하였다.

광역자치단체의 안전감찰제도는 현재 시행 초기단계로 제도가 본격적으로 시행되고 정착되어 가는 과정에서 다양 한 애로사항이 발생할 수 있으며, 이에 따른 개선방안을 마련할 필요가 있다. 따라서 관계 공무원 및 감찰 대상기관 의견 수렴 등을 통한 문제점 도출 및 제도 평가, 도출된 문제점 해결 등을 위한 다양한 후속연구가 필요할 것으로 판단된다. 특히 안전감찰 적용사례 수집을 통한 실제 적용에 의 문제점 및 이에 따른 개선방안 마련, 제도의 정착 및 원활한 감찰업무의 수행과 관련된 세부제도 시행 및 효율적 운영을 위한 추가적인 방안 마련 등이 필요할 것으로 예상된 다는 점에서 후속연구가 진행될 필요가 있다.

\section{감사의 글}

본 연구는 부산연구원 2019년 연구과제 “시민안전 확보를 위한 안전감찰 방안연구(현안연구 2019-04-861)"의 연구비 지원으로 수행되었으며, 해당 연구보고서의 내용 중 일부를 재구성하였습니다.

\section{References}

Cho, S. (2018). An establishment of 2019 safety audit and inspection master plan. Issue Report, Chungnam Institute.

Kim, K. (2018). Missions for anti-corruption effort in the safety field. Busan Development Forum, Vol. 174, pp. 62-69.

Kim, K., and Lee, J. (2019). A planning of the safety audit and inspection for ensuring the citizens' safety. Busan Development Institute.

Kim, S., and Choi, S. (2019). The direction of advanced 
safety inspection. Proceeding of 2019 Conference, Korean Society of Hazard Mitigation, p. 226.

Lee, J., Kwon, H., Lee, D., and Park, K. (2015). A study on establishing of the safety audit and inspection system and its development plan. Korea Disaster Prevention Association.

Lim, H. (2018). Review report for enactment of the administrative rule for violation of disaster management duty. Daejeon Metropolitan City.

Ministry of the Interior and Safety (MOIS). (2017). The safety audit and inspection casebook.

Park, K.-R., Soung, J.-H., Shin, H.-K., and Kim, D.-W.
(2012). Special juridical police force in South Korea. Korean Institute of Criminology.

Yang, J.Y., and Kim, S.S. (2019). Special judicial police for enhancing administrative power a study on the expansion of jobs: Based on the result of 10 years' operation of Seoul Metropolitan Police Judicial Police Team. Korean Security Journal, No. 58, pp. 59-80.

\begin{tabular}{|l|l}
\hline Received & May 2, 2019 \\
Revised & May 10, 2019 \\
\hline Accepted & October 23, 2019
\end{tabular}

